\title{
Ozaki Procedure: 1,100 patients with up to 12 years of follow-up
}

\author{
Ozaki prosedürü: 12 yıla varan takipte 1100 hasta
}

\author{
Shigeyuki Ozaki (D) \\ Department of Cardiovascular Surgery, Toho University, Ohashi Medical Center, Tokyo, Japan
}

Ozaki procedure or aortic valve neo-cuspidization basically includes replacement of aortic valve cusps by three native autologous pericardial cusps. Its midterm outcomes have been published previously. ${ }^{[1]}$ This video article presents the operative technique in a stepwise method. ${ }^{[2]}$

In our clinic, this operation was performed during 12 years from April 2007 to March 2019, and more than 1,100 patients were operated. The mean age of the patients was $67.7 \pm 14.9$ years. The etiology was aortic stenosis in $61.7 \%$, aortic insufficiency in $31.1 \%$, and both in $7.2 \%$ of the patients. The mean aortic cross-clamp and cardiopulmonary bypass times were $106.1 \pm 30.3$ and $151.3 \pm 36.9$, respectively. The overall survival rate is $84.6 \%$ and freedom from reoperation is $95.8 \%$ at 12 years.

This technique can be applied in patients with aortic stenosis, aortic regurgitation, infective endocarditis, and prosthetic valve endocarditis and those with non-tricuspid aortic valve with a similar method. The main strengths of the technique are the immediate superb hemodynamics after the operation and no anticoagulation requirement postoperatively. Regarding to the operative technique, there may be some additional points to be considered:

1. During the sizing of the cusps, the larger one should be selected, if one small or larger one does not exactly fit the sizer.
2. A bovine pericardium can also be used in selected patients, if native pericardium is not available. No calcification issue was experienced in our series.

3. A learning period usually includes the first 20 patients for such operation; therefore, the set up and technique should be supervised in the beginning.

4. If the difference between the sizing of each cusps is more than $2 \mathrm{~mm}$, a new commissure should be created to prevent misalignment between the cusps.

\section{Declaration of conflicting interests}

The authors declared no conflicts of interest with respect to the authorship and/or publication of this article.

\section{Funding}

The authors received no financial support for the research and/or authorship of this article.

\section{REFERENCES}

1. Ozaki S, Kawase I, Yamashita H, Uchida S, Takatoh M, Kiyohara N. Midterm outcomes after aortic valve neocuspidization with glutaraldehyde-treated autologous pericardium. J Thorac Cardiovasc Surg 2018;155:2379-2387.

2. Alhan C. Ozaki Procedure. Turk Gogus Kalp Dama 2019;27:451-3. 